Essay

\title{
Habituation and sensitisation: new thoughts about old ideas
}

Daniel T. Blumstein

Department of Ecology and Evolutionary Biology, University of California Los Angeles, U.S.A.

*Correspondence: D.T. Blumstein, Department of Ecology and Evolutionary Biology, 621 Young Dr. South, University of California, Los Angeles, CA 90095-1606, U.S.A. E-mail address: marmots@ucla.edu

People have written about habituation, a process that leads to declined responsiveness to a stimulus, as well as its counterpart—sensitisation — an increased responsiveness to a stimulus - for over 2000 years. And, while intensive research in the last century has led to well-supported generalisations about mechanisms of habituation, we have not developed a 'natural history' of habituation and tolerance which would help us predict, based on life history and natural history variation, how species will respond to humans and anthropogenic stimuli. The need for predictive models has never been greater. In this essay I will review generalisations about these learning processes and point out how a clear understanding of mechanism can be used to inform wildlife management and generate testable management interventions. I will also highlight unanswered questions 
about habituation and sensitisation, and establish the groundwork for developing a natural history of habituation and tolerance.

There once was a shepherd boy who was bored as he sat on the hillside watching the village sheep. To amuse himself he took a great breath and sang out, "Wolf! Wolf! The Wolf is chasing the sheep!"

Aesop ca. $5^{\text {th }}$ Century BC

Habituation is a process that leads to decreased responsiveness to a stimulus with repeated presentation and is often adaptive in that it makes it less likely that individuals will respond to harmless stimuli. Found throughout the animal kingdom, some plants have also been shown to habituate (Jensen, Dill, \& Cahill, 2011). However, habituation may also have consequences. Aesop recognized the consequences of habitation 2500 years ago when he noted that the boy who cried wolf would ultimately be ignored when he needed help to fend off a real wolf.

Habituation's counterpart is sensitisation — the increased responsiveness to a stimulus with repeated presentation. Sensitisation may be adaptive if it helps animals avoid potentially risky or costly situations. Being sensitised to the sound of bees may help elephants avoid getting their sensitive trunks stung (sensu King, Douglas-Hamilton, \& Vollrath, 2007), and may help allergic humans avoid an anaphylactic reaction. But it too may be costly. For instance, while drug addiction is usually thought to involve some 
degree of tolerance to drugs, indeed, it also involves sensitised responses that can be used diagnostically because greater salience is attached to the drugs and drug-associated cues (Steketee \& Kalivas, 2011). Living without risk is impossible (Sagarin, Alcorta, Atran, et al., 2010) and the public may become sensitised to real or manufactured threats repeated by the press (e.g. consider the US government assertions that Iraq had weapons of mass destruction, or the American response to Ebola cases being treated in the United States in September-November 2014). Over-reacting to risk can lead to costly foreign policy missteps and costly public health responses.

Wildlife managers and conservation biologists care deeply about these processes because there is variation in the degree to which species' tolerate humans and our various associated stimuli (Blumstein, 2014). Tolerance is seen when animals permit closer approaches by humans without overtly responding or fleeing (e.g. Herrero, Smith, DeBruyn, Gunther, \& Matt, 2005; Samia, Nakagawa, Nomura, Rangel, \& Blumstein, 2015). This tolerance may emerge from habitutation-like processes or from more tolerant animals settling in areas where they encounter humans, while less tolerant ones actively avoid humans (e.g. Samia, Nakagawa, et al. 2015). We may see apparently tolerant animals because of lack of resources elsewhere, resulting in dwindling resources within a patch, increased competition for remaining resources, and increased tolerance to disturbance (e.g. Owens 1977). Thus, because tolerance could not indicate habituation, it is essential to understand when habituation occurs. However, not all species tolerate increased human exposure; some species apparently sensitise to humans and thus may avoid or have heightened escape responses to them as human activity increases (e.g., Blumstein, 2013). 
There are several main areas of wildlife management/conservation that can benefit from a deep understanding of these processes and their outcome - tolerance or susceptibility with respect to humans. The first area is attempting to reduce human animal conflicts through the use of animal repellents. In this case habituation can severely reduce the effectiveness of the management plan as has long been known by managers. The second concerns cases where the goal of the manager is to habituate animals to anthropogenic activities. The third deals with the transferability of habituation from humans to other potential predators, a behavioural strategy that, if common, could have unfortunate conservation outcomes. While managers work to address these issues on the ground, greater communication and collaboration with behavioral biologists might lead to novel management strategies (Blumstein \& Fernández-Juricic, 2010).

First, wildlife-human conflict situations require managers to decrease tolerance of animals to humans and human-related stimuli so that animals avoid humans and our resources. These situations are commonly seen when bears (Elfström, Zedrosser, Støen, \& Swenson 2014), birds (Belant, Seamans, Gabrey, \& Ickes, 1993), and rodents are attracted to human garbage, or when ungulates and primates eat crops (Naughton-Treves, 1998; O’Connell-Rodwell, Rodwell, Rice, \& Hart, 2000), and when marine mammals eat fish from human fisheries (Northridge, 1991). However, a state of increased tolerance may emerge from habituation-like processes that follow repeated exposure to potentially alarming stimuli or repellents and that render them ineffective.

Second, anthropogenic human disturbance may scare or otherwise interfere with animals' behaviour (Klein, Humphrey, \& Percival, 1995; Steven, Pickering, \& Castley, 2011). A variety of factors may modify behaviour including experience with more 
humans, human development, or activities--even seemingly benign ones like ecotourism and bird watching. Thus, when the goal is to not lose species as human impacts increase, we may aim to increase tolerance of animals to humans. The problem, however, is that not all species habituate.

In the remainder of this essay, I will more formally define habituation, sensitisation, and tolerance. I will review generalisations about these processes. I will then discuss why these processes are important to wildlife managers and conservation biologists because not all species habituate, and tolerance based on observed behaviours may not be benign and how and why one way to study them capitalises on quantifying the flight initiation distance in response to approaching humans. Then, I will outline a research programme by which we can develop a natural history of habituation and discuss future research needs.

\section{THE RULES OF HABITUATION}

Habituation has been formally and comprehensively reviewed by Rankin, Abrams, Barray, et al. (2009). Habituation has been studied for over a century and in their authoritative review, Rankin et al. defined habituation as “...a behavioral response decrement that results from repeated stimulation and that does not involve sensory adaptation/sensory fatigue or motor fatigue" (p. 136). In more general terms, habituation is a type of 'single-stimulus' learning that allows animals to avoid costly responses in situations where there is no benefit from responding to repeated stimulation. 
Bejder, Samuels, Whitehead, Finn, \& Allen (2009) systematically reviewed how these terms are used (and mis-used) in the wildlife management literature. They quoted Nisbet (2000: 315) who wrote that "Habituation and sensitization are processes, that occur over time, and that predict changes in tolerance (i.e., the intensity of disturbance that an individual tolerates without responding in a defined way"). Viewed this way, tolerance is a 'state' and changes in tolerance reflect prior experiences. Managers typically measure tolerance in human impact studies but it was the processes of habituation, habituation-like processes, or sensitisation, or the differences in habitatselection among individuals that ultimately lead to differences in tolerance.

Rankin et al. (2009) made a number of generalizations about habituation. I will focus on a number of these because knowledge of them can help design protocols to enhance or inhibit habituation and habituation-like processes. After this brief summary, I will attempt to apply some of these insights to concrete management problems.

First, regarding habituation, there should be a non-linear, asymptotic decline, in the frequency or magnitude of a response with repeated or on-going stimulation. After some time or number of repetitions, we should not expect more habituation. From a wildlife manager's perspective, animals that habituate should do so predictably to repeated exposure to anthropogenic stimuli.

Second, there can be spontaneous recovery (to pre-stimulus levels) if the stimulus is withheld which means that if habituation is a goal, some degree of repeated stimulation is required. From a manager's perspective, intermittent exposure to anthropogenic stimuli, 
with long intervals between exposures, may not lead to habituation (Rodríguez-Prieto \& Fernández-Juricic 2005).

Third, after a series of stimulus repetitions and spontaneous recoveries, habituation becomes more rapid. This means that animals are likely to learn to re-habituate more quickly with prior experience. From a manager's perspective, if habituation is desired, intense bouts of experience with anthropogenic stimuli that are separated in time, will ultimately lead to habituation. However, this raises concerns when the goal is to prevent animals from eating at dumps or other localised sources of food if individuals visiting them are intermittently hazed (e.g. Werner \& Clark, 2006).

Fourth, more frequent stimulation leads to more rapid habituation, which means that if habituation is the objective of exposure to stimuli, short intervals between exposures to stimuli will be particularly effective.

Fifth, repeated stimulation after the asymptote has been reached may delay spontaneous recovery. Mangers thus may face problems when they seek to haze animals away from specific areas because repeated stimulation will maintain habituated responses.

Sixth, stimulus strength is important: 'weaker' stimuli lead to more rapid habituation while 'strong' stimuli might not result in habituation. This means that lower intensity stimuli (amplitude, size, color, etc.) may be more effective if the goal is to habituate animals to anthropogenic stimuli.

Seventh, it is possible for animals to dis-habituate or have their response recover. One important factor that influences dis-habituation is the presentation of another 'strong' stimulus. This is an important characteristic because, as Rankin et al. (2009) note, 
it is the only characteristic that ties a proximate mechanism of habituation to its ultimate benefit - habituating to innocuous stimuli while maintaining the ability to respond to novel stimuli.

Eighth, even though a stimulus may cause dis-habituation, repeated exposure to that stimulus may lead to habituation. Again, from a manager's perspective, if habituation is desired, these are important characteristics to know, but they also create real challenges when trying to haze animals away from specific resources.

Ninth, habituation can be transferred from one stimulus to another. Such transfer of habituation has important implications because it is a fundamental way that we can identify the natural categories into which animals classify stimuli (e.g. categorical perception-Harnad, 1987). If, for example, by habituating to humans, a particular prey also habituated to another terrestrial, mammalian predator-say a fox (Vulpes sp.)--we would infer that humans and foxes are perceived similarly. There are some data that suggest that after habituating to benign humans animals may transfer their response to humans to their natural predators (Mccleery, 2009), but more data are needed to understand how widespread this is and the conditions under which it emerges (Geffroy, Samia, Bessa, \& Blumstein, 2015). However, by habituating to benign humans, animals are certainly more vulnerable to humans with consumptive intent (Geffroy et al., 2015). This may be a real problem in protected areas that are subjected to wildlife poachingsuch as the Virunga National Park gorillas (Gorilla gorilla) in the Democratic Republic of Congo (Kasereka, Muhigwa, Shalukoma, \& Kahekwa, 2006). Herrero et al. (2005), and Smith, Herrero, \& DeBruyn (2005) noted that brown bears (Ursus arctos) habituate 
to bears as well as humans and the fact that bears habituate to other bears may predispose them to habituate to humans.

Tenth, there is the potential for long-term habituation to stimuli. From a managers' perspective, this may be a desirable feature - if the goal is to reduce human impacts on wildlife, or a very undesirable feature - if the goal is to repel animals by using some sort of hazing device (http://icwdm.org/ControlMethods/Hazing.aspx accessed 24 February 2015). Developing hazing devices to protect wildlife has been an active area of applied research. Indeed, preventing large carnivores from eating livestock has led to the creation and evaluation of disruptive-stimuli (such as fladry — small flags tied to fence lines, and a variety of noise makers that are triggered by a predator's presence), as well as aversive stimuli (such as training collars and the deployment of painful stimuli (e.g. Shivik 2006). Shivik (2006) reviews the duration of effectiveness of various tools created to attempt to manage human-carnivore conflicts and found that many became ineffective rather rapidly and may work to various degrees on different carnivores (e.g. Shivik, Treeves, \& Callahan, 2003). Effectiveness wanes over time as animals learn to ignore relatively benign threats. Thus, currently available repellents may be best suited for relatively short periods of application in relatively high-risk situations (Shivik, 2006).

\section{WHY MECHANISM MATTERS}

A state of tolerance could be developed by habituation and habituation-like processes. However, apparent tolerance to human disturbances could also be caused, as Bejder et al. (2009) point out, by displacement, whereby individuals vary in the degree of disturbance 
they are able to tolerate and that they sort themselves out according to this variation in disturbance tolerance. In this case, we would see spatial variation in behavioural (or physiological) responses that did not result from habitation. Because habituation, as a mechanism, has certain characteristics, knowing when habituation is the mechanism responsible for tolerance could have important management implications if the goal is to either increase the degree of habituation or to delay the onset of habituation.

There are least two other processes that could lead to spatial variation in tolerance (Bejder et al., 2009). First, there could be physiological differences caused by repeated exposure to disturbances, which can affect the sensitivity of animals to similar disturbances, for example, deafening that resulted from prolonged exposure to loud noises. Second, there could be ecological traps that may affect certain individuals or those in certain locations. Van Horne (1983) pointed out that habitat quality should not be inferred from the distribution of animals, but rather where individuals had the greatest fitness. Later, Gill, Norris, \& Sutherland (2001) noted that animals may be lured to areas with a particular resource even though their fitness was lower in that patch because of human disturbance. They cautioned that inferring suitable habitat from relative abundance was fraught with risk. Bejder et al. (2009: 182) summarized aptly: "mechanisms that do not involve true habituation are unlikely to denote natural or beneficial outcomes for wildlife affected by disturbance". Thus, it is essential to understand the conditions under which true habituation, rather than other mechanisms that might explain apparent tolerance, occurs and the conditions under which it does not. 


\section{APPLICATION: PREVENTING HABITUATION}

While aversive conditioning has been used by wildlife managers for years (e,g. Kloppers, St. Clair, \& Hurd, 2005; Leigh \& Chamerblain, 2008), when the goal is to manage human-wildlife conflict from the position of reducing the likelihood of habituating to repellents, fear conditioning may be a particularly promising technique (Schakner \& Blumstein, 2013, 2016). Indeed, the ultimate goal of using potentially harmful and aversive deterrents, like very loud and painful sounds, should be to not have to continually use them. Thus, creating anxiety that leads to avoidance of a contested area or resource should be an effective and more welfare-friendly/ethical strategy.

Unlike habituation or sensitization, which are examples of single stimulus learning where stimuli are not paired with other predictive stimuli, fear conditioning is a method of associative learning that pairs a painful or startling unconditioned stimulus (US) with a benign stimulus (CS) that ultimately predicts the US. If applied successfully, a few pairings of the benign stimulus with the painful/aversive stimulus will create fear or anxiety in the target subjects when they experience the benign stimulus. While there may need to be additional presentations of the painful/aversive US to prevent extinction of responses to the benign CS, it will have to be used much less than had the US been repeatedly presented alone. True fear conditioning is not simply aversive conditioning because true fear conditioning ensures that the aversive stimulus is sufficiently painful/aversive as to cause an unconditioned startle response. What is needed is to develop and properly evaluate fear-conditioning protocols to create effective and welfarefriendly/ethical deterrents. 


\section{APPLICATION: PROMOTING HABITUATION}

There are a variety of situations where we might wish to promote habituation. For instance, if wildlife-human interactions are inevitable (a new hiking trail is being built, a formerly closed area is opened up to ecotourists, etc.) might there be ways to habituate wildlife to increased expected exposure to humans? The list of Rankin et al.'s (2009) generalizations offers great promise for management interventions. But, aside from researchers habituating animals to observer presence (e.g. Goodall, 1986), and studies that have demonstrated that habituation might extend to the specific location from which a disturbing stimulus approaches an individual (Raderschall, Magrath, \& Hemmi, 2011), I am aware of no experimental studies that have tried to apply them in a management context specifically to habituate animals to anthropogenic disturbance. There are some observational studies that have capitalized on bear viewing that suggest that concentrated food sources (natural or artificial) concentrate bears, which habituate first to each other, and then to people (e.g. Herraro, et al., 2005). The lack of experimental studies is striking in part because treatments of post-traumatic stress disorder (PTSD) in humans, as well as behavioural therapies to reduce phobias, both involve repeated exposure to benign stimuli with the aim of reducing responsiveness to them (e.g. Wilson, Friedman, \& Lindy 2001). There is much potentially to learn from human therapies that could be applied to wildlife management.

By contrast, there are many studies that have reported differences, both over time and space, as a function of exposure to specific human-related stimuli (e.g. Li, Monclús, Maul, 
Jiang, \& Blumstein, 2011; Viblanc, Smith, Gineste, \& Groscolas, 2012). It is essential, from a management perspective, to recognize that overt behavioural tolerance may not equal physiological tolerance (e.g. Ellenberg, Mattern, \& Seddon, 2013) and whenever possible it is essential to try to study both the overt behavioural responses and less overt physiological ones (e.g. Tarlow \& Blumstein, 2010).

\section{APPLICATION: EVALUATING HABITUATION TRANSFER}

It is possible that under certain conditions animals that habituate to humans become more vulnerable to predators (Geffroy et al., 2015). Formally, the transfer of habitation from one stimulus to another type of stimulus means that the two stimuli are categorically classified into the same class of stimuli (Harnad, 1987). While humans and coyotes may indeed both be members of a category of terrestrial mammalian predators, many species have sophisticated and nuanced predator discrimination abilities (e.g. Relyea, 2003; Liesenjohann \& Eccard, 2008). Thus, some degree of habituation among very similar types of stimuli might be expected but we may not generally expect that by habituating to humans prey will suddenly become vulnerable to other predators unless human presence creates a human shield (Berger, 2007), which reduces all threats on animals (Geffroy et al., 2015).

We asked whether dik-diks (Madoqua guentheri), a small African ungulate that is eaten by about 36 species of mammals and birds, transfers habituation from humans to predators in a situation where there was no strong human shield. To do so, we broadcast jackal (Canis adustus) calls and bird song within about $0.5 \mathrm{~km}$ of human habitation and $>$ 
$0.5 \mathrm{~km}$ of human habitation. We assumed that dik-diks living within $0.5 \mathrm{~km}$ of humans were habituated to humans. We found that human-intolerant dik-diks, those living $>0.5$ $\mathrm{km}$ of humans, were unable to discriminate between the sounds of predators and benign sounds. From this we concluded that ecotourists at more pristine places are likely to disturb animals and interfere with their risk assessment (Coleman, Richardson, Schechter, \& Blumstein 2008).

From first principles, one might initially assume that animals that are not overtly persecuted by people, and that have large home ranges which includes human areas, should be tolerant to, and possibly habituated to, human presence throughout their home range. However, we often find that context is very important for habituation and one might also assume that non-persecuted individuals might habituate to the specific areas where human disturbance is present. We asked whether mule deer (Odocoleus hemionis), that are not hunted during the summer, discriminate yellow-bellied marmot alarm calls from white-crowned sparrow song within $0.5 \mathrm{~km}$ of human habitation and $>0.5 \mathrm{~km}$ form human habitation. Similar to our dik-dik results, we found that deer were able to discriminate the sounds when studied relatively close to humans but were unable to discriminate the sounds farther away from humans where they were generally more responsive to our presence (Carrasco \& Blumstein, 2012).

I acknowledge that there are a number of factors other than learning processes-most are in some way related to the location of valuable resources - that could explain location specific differences in tolerance to humans. Nonetheless, does $0.5 \mathrm{~km}$ have some special meaning? Studies of how mule deer respond to approaching humans identified a threshold somewhere between $300 \mathrm{~m}$ and $700 \mathrm{~m}$ whereby they fled sooner after 
becoming alerted when farther from human settlements than closer to human settlements (Price, Strombom, \& Blumstein, 2014). Studies of how western gull (Larus occidentalis) flight initiation distance (FID) varied as human disturbance declined spatially showed a rapid increase in FID with declining human visitation to a beach (Webb \& Blumstein, 2005). And, studies of birds on either side of a fence that restricted human access showed that four species of shorebirds were more tolerant of human approach where they were exposed to ecotourists and less tolerant in an adjacent area on the other side of the fence. Indeed, there were no significant differences in FID between the fenced side of the wetland and a nearby wetland that was closed to the public (Ikuta \& Blumstein, 2003).

Humans may also shield prey from specific predators that are less tolerant of humans in specific locations. Such human shields have been reported to change the behaviour of some ungulates (e.g. Berger 2007; Shannon, Cordes, Hardy, et al., 2014), and primates (e.g. Nowak, le Roux, Richards, Scheijen, \& Hill, 2014), may help drive trophic cascades (e.g. Waser, Price, Blumstein, et al., 2014). Therefore, the human shield effect is important to consider when trying to understand the conditions under which animals become tolerant of humans, whether via habituation or other mechanisms (Geffroy et al., 2015).

There is a growing literature on the spatial ecology of fear (e.g. Brown, 1999; Brown \& Kotler, 2007; Ditchkoff, Saalfeld, \& Gibson, 2006; Zimmerman, Nelson, Wabakken, Sand, \& Liberg, 2014; St. Clair, Found, Gangadharan, \& Murray, 2016) and much could be gained by even more detailed studies of risk assessment in an explicitly spatial context. The goal would be to fundamentally understand what ecological, morphological, behavioural, and life history factors influence the distances that tolerance, and possibly 
habituation, to humans extends. From first principles it will likely depend on a species' perceptual active space (e.g. Lima \& Zollner, 1996; St. Clair et al., 2016) and home range size. Spatial detection maps, which reflect areas around an animal where the probability of threat detection are higher based on the visual system configuration, define the perceptual active space (Tyrell \& Fernández-Juricic, 2015). Once these are understood, then we might expect that species that have large home ranges and habituate to humans at a specific location may be more likely to transfer that perceived safety to other parts of their home range. However, what's completely unknown is how site-specific risk factors may directly or interactively influence the spatial ecology of fear. For instance, if a specific habitat type (e.g. dense cover) is associated with increased predation risk, are animals equally likely to be tolerant in or to habituate to these specific areas within a human-dominated landscape? More studies are thus warranted.

\section{APPLICATION: UNDERSTANDING ANTHROPOGENIC DISTURBANCE}

There are many situations where the establishment of hiking trails, roads, or human development leads to the loss of intolerant species. How can we develop a better understanding of which species are likely to be more or less tolerant to human disturbance? And, more importantly, can we distinguish a change in tolerance from other factors, such as successful avoidance by modifying resource use around humans (e.g. Zimmerman et al., 2014), as the driver of coexistence or the failure to coexist with humans? I focus on insights from studies generated by quantifying flight initiation 
distance because these studies have created a large comparative data set that allows us to draw generalizations.

We know that humans change animals' behaviour and a key to understanding how is to view people as predators (Frid \& Dill, 2002). We know that when predators approach, animals often flee and hide from them. Flight initiation distance is the distance at which an individual flees and approaching person. It's a method to quantify perception of predation risk and it's a method that can aid in wildlife management.

Flight initiation distance should, and does, vary quite dynamically (Ydenberg \& Dill, 1986; Cooper \& Blumstein 2015). So, before we embark on comparative studies, we should have some confidence that FID is a species-specific trait. Blumstein, Anthony, Harcourt, \& Ross (2003) showed that FID varied in 8 species of Australian shorebirds studied at 6 sites, chosen because they varied in human visitation, varied, but without significant interactions across sites. This means that flighty species are relatively flighty wherever they are studied and provides some assurance that FID can be viewed as a species-specific trait. Subsequent studies have identified some phylogenetic signature of FID (e.g. Møller \& Garamszegi, 2012; Møller, Samia, Weston, et al., 2014), which provides additional support for the hypothesis that FID can be viewed as a speciesspecific trait for comparative study. Importantly, and somewhat intriguingly, a phylogenetic signal in FID is not always found (e.g. Cooper, Pyron, \& Garland 2014; Symonds, Weston, Robinson, \& Guay, 2014).

There is a huge literature on FID, which mostly has focused on birds (Møller, 2015), mammals (Stankowich \& Reimers, 2015) and lizards (Cooper, 2015; Samia, Blumstein, 
Stankowich, \& Cooper, 2015), that has identified a variety of extrinsic and intrinsic factors that influence FID (Stankowich \& Blumstein, 2005). For instance, body size (Blumstein, 2006) and starting distance or alert distance (Blumstein 2003, 2010; Samia, Nomura, \& Blumstein, 2013; Samia \& Blumstein, 2014) explain a considerable amount of variation in FID: large animals and those which are approached and alert at greater distances flee at greater distances. While a relatively small comparative study found no effect of eye size on FID (Blumstein, Fernández-Juricic, LeDee, et al., 2004), a larger study found that birds with larger eyes flee at greater distances (Møller \& Erritzøe, 2010). Thus, some evidence suggest aspects of vision influence FID. Species that eat live prey have larger FIDs than those that do not (Blumstein, 2006) as do cooperative breeders. Species that first reproduce at later ages (Møller \& Garamszegi, 2012), those that are in more open habitats (Møller \& Erritzøe, 2010, but see Blumstein, 2006), and those with faster basal metabolic rates (Møller, 2009) all flee at greater distances.

Remarkably, however, most of these studies have not followed marked individuals. Since one of the key questions is whether individuals habituate or not to repeated disturbance, this is a major shortcoming in our knowledge about how FID can be used to inform management. To determine whether individuals habituate to repeated approaches, it is essential to study marked individuals.

Over the past decade, we have studied FID in a marked population of yellow-bellied marmots studied at the Rocky Mountain Biological Laboratory, the site of a long-term research project that began in 1962 (Blumstein, 2013; Armitage, 2014). Marmots were experimentally approached one or more times annually. After controlling for a variety of other factors that influence FID, we found that older marmots, but not pups, allow people 
to approach them more closely after repeated approaches and thus show evidence of habituation-like processes.

Carrete \& Tella $(2010,2013)$ repeatedly measured FID in individually-marked burrowing owls (Athene cunicularia). They estimated the repeatability of FID, which is a measure of intra-individual consistency, and found that there was substantial repeatability (0.84-0.92). They also found significant inter-individual variation in FID that was maintained over repeated experimental approaches. Thus, some owls failed to habituate. They hypothesised that more sensitive owls settled in places with less human disturbance, while more tolerant owls were able to coexist with human disturbance (Carrete \& Tella, 2010).

In addition, some species may sensitise. In a study of 14 species of California coastal chaparral birds, only four species had significantly different FIDs when studied in areas with relatively more human visitation than areas that were less frequented by humans. However, and somewhat unexpectedly, these four species had greater FIDs when exposed to more people (Blumstein, 2013). The other 10 species had no significant differences in FID as a function of quantifiable differences in human visitation. What could explain this apparent sensitisation?

According to the dual process theory of habituation, an observed behavior after repeated exposure to a stimulus represents the sum of the two underlying learning processes of habituation and sensitisation (Groves \& Thompson, 1970). Virtually nothing is known about the conditions under which sensitisation dominates habituation in the wild. 
I suggested that the perhaps species living in limited habitats (e.g. wetland fragments), may be more likely to habituate than those living in more contiguous habitats (e.g. chaparral) because those that live in remnant fragments may have already gone through a sorting process that eliminated less tolerant species or individuals (Blumstein, 2013). I called this the 'contiguous habitat hypothesis' and suggested that it needs proper testing by evaluating it in other habitats, with more species, and different types of disturbance. Indeed, the importance of contiguous habitat may also vary by whether a species is a generalist or a specialist with specialists tolerating more disturbance in fragmented landscapes because they have no other options that to tolerate disturbance.

\section{CONCLUSIONS: DEVELOPING A NATURAL HISTORY OF HABITUATION}

A fox who had never yet seen a lion, when he fell in with him for the first time in the forest was so frightened that he was near dying with fear. On his meeting with him for the second time, he was still much alarmed, but not to the same extent as at first. On seeing him the third time, he so increased in boldness that he went up to him and commenced a familiar conversation with him.

Aesop ca. $5^{\text {th }}$ Century BC

I suggest that we must develop a natural history of habituation and processes that lead to tolerance. What would this look like? I suggest we want to try to predict how species will respond to humans and our stimuli. We know that not all species habituate. Why? What future research is needed to develop better predictive models? Developing a fullblown natural history of habituation must be integrative in scope (it must be based on a 
wide range of physiological stress responses) and requires greater knowledge of all of species' sensory abilities. It would also require understanding all sensory abilities. Such data are not currently available across a wide range of species living in a variety of habitats and under a variety of anthropogenic disturbances. Thus, for a first stab, I will restrict it to insights that can be gained by studying FID.

We know that large species have greater FIDs than small species (Blumstein, 2006), and body size is also a key predictor of the magnitude of habituation-like responses seen (Samia et al., 2015). Thus, large species might simultaneously be more likely to be initially disturbed by humans engaged in benign activities, but paradoxically, they might also be more likely to habituate to reduce the costs associated with disturbance. If large species pay a relatively larger cost of disturbance, it is large species that should therefore have a relatively greater benefit from habituation. This hypothesis requires proper testing.

Life history and natural history variation may also be important predictors of the degree to which species habituate to and tolerate human disturbances. We know that sociality and other life history factors influence FID (Blumstein, 2006) and this in turn should select for greater benefits from habituation.

We must also understand past selection. Sih (2013) emphasised that decision rules animals employ are the result of past selection. The degree of match between current and historical threats should permit us to understand how and when species may (or may not) habituate to or more generally tolerate specific types of disturbance. Truly novel disturbances may be more difficult to tolerate than those that share features with other known threats. And, truly novel disturbances might also lead to a level of tolerance 
(possibly via habituation) that, at some point, could prove lethal (e.g. animals adapting to frequent vehicle traffic, the novel disturbance, but then unable to respond adequately to instances of direct vehicle approach at moderate to high speeds in marine, terrestrial, or airborne situations).

We must develop a better understanding of the spatial scale of habituation. It can be stark (e.g. with a fence), or gradual and occur over several km. Does body size, acting through home range size, and therefore expected experience influence the spatial scale of habituation? Or, might habituation be very site specific, which means that individuals are differentially tolerant to humans in different locations. Studies are needed to disentangle these alternative hypotheses in more than one species.

Similarly, the contiguous habitat hypothesis must be tested. Does the degree of habitat continuity really predict whether species habituate or not? Has there been a 'filtering' process that occurred in fragmented habitats? Future studies in different systems will let us know more about the generality of the hypothesis.

Ellenberg, Mattern, \& Seddon (2009) noted that sex, temperament and previous experience with humans affect whether yellow-eyed penguins (Megadyptes antipodes) habituate or sensitise to repeated human visitation. Calm individuals were more likely to habituate as were females. Are such patterns generalisable? Does this mean that certain types of individuals will be systematically more disturbed by human activities than others? Such studies are urgently needed because differential disturbance potential will change the mix of personality types in the population and this may affect population persistence. 
We must develop a better understanding of the fitness consequences of habituation to humans. Are the results from dik-diks generalizable to other species? Is there any evidence that habituating to humans makes species more vulnerable to natural predators? Fortunately, to date, evidence for this is scarce, but that does not mean that it never happens.

We must develop a better understanding of individual differences in risk tolerance. Adopting a framework to study phenotypic plasticity gives us two ways to quantify individual tolerance: individuals may differ in their expected value (estimated with a BLUP: best linear unbiased predictor-Henderson, 1975), or they may differ in the slope at which they habituate (e.g. Dingemanse \& Dochtermann, 2013). What are the patterns that different species show? Are there any generalisations that can be made about these patterns? What explains variation in these patterns?

Managers should try to apply insights from this corpus of knowledge to solve applied problems. However, to advance the field, applications should be in the context of adaptive management experiments (Walters \& Holling, 1990; see also Blumstein, 2007). Blumstein \& Berger-Tal (2015) outline a work-flow through which behavioural ideas are tested to see if they can successfully be used to solve management problems and if so, then their comparative efficacy is evaluated. By including comparative efficacy evaluation, the relative utility of behavioural interventions can be compared to more traditional wildlife management interventions. In the context of managing human-wildlife conflicts, more stimuli (both in quantity and quality) may be more disturbing and hence, more effective, as might stimulus location and timing (also see Conover, 2002). And, 
while fear conditioning seems to offer great promise, it is essential to properly evaluate fear-conditioning paradigms to reduce human-wildlife conflict.

Bejder et al. (2009) noted the importance of developing and applying models based on individual decisions. To do so we must identify key internal and external factors that influence risk assessment. Meta-analyses of FID (Stankowich \& Blumstein, 2005; Møller, 2015; Samia et al., 2015) and comparative analyses (e.g. Blumstein, 2006; Díaz, Møller, Flensted-Jensen, et al., 2013; Møller et al., 2014) are good first steps.

It is, however, important to realise that results from comparative analyses that include a diversity of species with a broad range of trait values (e.g. body masses) might not apply at the intraspecific level. For instance, while body mass explains much of the interspecific variation in FID, body mass variation does not significantly explain variation among individually-marked, yellow-bellied marmots' FID (Petelle, McCoy, Alejandro, et al., 2013). One likely explanation is that the range of the variation within a species is substantially less than that found between species. If generally true, one must be somewhat skeptical about using the results of comparative analyses to identify key factors that influence a given species' behaviour without validating them in species of interest. Nonetheless, state-based models and approaches may be particularly important since they put decisions into a life-history context by which individuals must trade-off starvation versus predation risk (e.g. Gill et al., 2001; Rhodes \& Blumstein, 2007). And, Sih (2013) makes a strong case for focusing on individual decisions in situations where there has been human caused rapid environmental change (HIREC). 


\section{Acknowledgements}

I thank Bruce Schulte and Esteban Fernández-Juricic for encouraging me to develop my 2013 ABS Conservation Symposium talk into a full-blown essay, and two extremely constructive reviewers (one of which was Colleen Cassady St. Clair) for their incisive comments and extensive thoughts. I also thank the NSF for support of my marmot fieldwork, which provides necessary grounding and stimulation for many of these ideas. Some of my ideas about habituation have emerged from discussions with my friends and colleagues_-particularly Zac Schakner, Oded Berger-Tal, Diogo Samia, Colleen, Maud Ferrari, and Andrea Griffin — to whom I am grateful. Zac and Oded also read and commented on early versions of the MS.

\section{References}

Armitage, K. B. (2014). Marmot biology: sociality, individual fitness, and population Dynamics. Cambridge: Cambridge University Press.

Bejder, L., Samuels, A., Whitehead, H., Finn, H., \& Allen, S. (2009). Impact assessment research: use and misuse of habituation, sensitisation and tolerance in describing wildlife responses to anthropogenic stimuli. Marine Ecology Progress Series, 395, 177-185.

Belant, J. L., Seamans, T. W., Gabrey, S. W., \& Ickes, S. K. (1993). Importance of landfills to nesting herring gulls. Condor, 95, 817-830.

Berger, J. (2007). Fear, human shields and the redistribution of prey and predators in protected areas. Biology Letters, 3, 620-623. 
Blumstein, D. T. (2007). Darwinian decision making: putting the adaptive into adaptive management. Conservation Biology, 21, 552-553.

Blumstein, D. T. (2003). Flight initiation distance in birds is dependent on intruder starting distance. Journal of Wildlife Management, 67, 852-857.

Blumstein, D. T. (2006). Developing an evolutionary ecology of fear: how life history and natural history traits affect disturbance tolerance in birds. Animal Behaviour, 71, 389-399.

Blumstein, D. T. (2010). Flush early and avoid the rush: a general rule of antipredator behavior? Behavioral Ecology, 21, 440-442.

Blumstein, D. T. (2013). Attention, habituation, and antipredator behaviour: implications for urban birds. Avian Urban Ecology: behavioural and Physiological Adaptations, 41.

Blumstein, D. T. (2013). Yellow-bellied marmots: insights from an emergent view of sociality. Philosophical Transactions of the Royal Society of London B: Biological Sciences, 368(1618), 20120349.

Blumstein, D. T. (2013). Attention, habituation, and antipredator behaviour: implications for urban birds. In D. Gill \& H. Brumm (Eds.) Avian Urban Ecology: Behavioural and Physiological Adaptations, 41-53.

Blumstein, D. T., Anthony, L. L., Harcourt, R., \& Ross, G. (2003). Testing a key assumption of wildlife buffer zones: is flight initiation distance a species-specific trait? Biological Conservation, 110, 97-100.

Blumstein, D. T., \& Berger-Tal, O. (2015). Understanding sensory mechanisms to develop effective conservation and management tools. Current Opinion in Behavioral 
Sciences, 6, 3-18.

Blumstein, D.T., \& Fernández-Juricic, E. (2010). A primer on conservation behavior.

Sunderland, MA: Sinauer Associates, Inc.

Blumstein, D. T., Fernández-Juricic, E., Zollner, P. A., \& Garity, S. C. (2005).

Inter-specific variation in avian responses to human disturbance. Journal of Applied Ecology, 42, 943-953.

Brown, J. S. (1999). Vigilance, patch use and habitat selection: foraging under predation risk. Evolutionary Ecology Research, 1, 49-71.

Brown, J. S., \& Kotler, B. P. (2007). Foraging and the ecology of fear. In D. W.

Stephens, J. S. Brown, \& R. C. Ydenberg (Eds.), Foraging: behavior and ecology (pp. 438-480). Chicago: University of Chicago Press.

Carrasco, M. F., \& Blumstein, D. T. (2012). Mule deer (Odocoileus hemionus) respond to yellow - bellied marmot (Marmota flaviventris) alarm calls. Ethology, 118, 243-250.

Carrete, M., \& Tella, J. L. (2010). Individual consistency in flight initiation distances in burrowing owls: a new hypothesis on disturbance-induced habitat selection. Biology Letters, 6, 167-170.

Carrete, M., \& Tella, J. L. (2013). High individual consistency in fear of humans throughout the adult lifespan of rural and urban burrowing owls. Scientific Reports, 3, 3524.

Coleman, A., Richardson, D., Schechter, R., \& Blumstein, D. T. (2008). Does habituation to humans influence predator discrimination in Gunther's dik-diks (Madoqua guentheri)? Biology Letters, 4, 250-252.

Conover, M. R. (2002). Resolving human-wildlife conflicts: the science of wildlife 
damage management. Boca Raton, FL: CRC Press.

Cooper, W. E., Jr., \& Blumstein, D. T. (Eds.) (2015). Escaping from predators: an integrative view of escape decisions and refuge use. Cambridge: Cambridge University Press.

Cooper, W. E., Jr. (2015). Reptiles. In W. E. Cooper, Jr. \& D. T. Blumstein (Eds.), Escaping from predators: an integrative view of escape decisions (pp. 113-151) Cambridge: Cambridge University Press.

Cooper, W. E., Pyron, R. A., \& Garland, T. (2014). Island tameness: living on islands reduces flight initiation distance. Proceedings of the Royal Society B: Biological Sciences, 281, 20133019.

Díaz, M., Møller, A. P., Flensted-Jensen, E., Grim, T., Ibáñez-Álamo, J. D., Jokimäki, J., . . Tryjanowski, P. (2013). The geography of fear: a latitudinal gradient in antipredator escape decisions of birds across Europe. PLoS ONE, 8, e64634.

Dingemanse, N. J., \& Dochtermann, N. A. (2013). Quantifying individual variation in behaviour: mixed - effect modelling approaches. Journal of Animal Ecology, 82, 3954.

Ditchkoff, S. S., Saalfeld, S. T., \& Gibson, C. J. (2006). Animal behavior in urban ecosystems: modifications to human-induced stress. Urban Ecosystems, 9, 5-12.

Elfström, M., Zedrosser, A., Støen, O. G., \& Swenson, J. E. (2014). Ultimate and proximate mechanisms underlying the occurrence of bears close to human settlements: review and management implications. Mammal Review, 44, 5-18.

Ellenberg, U., Mattern, T., \& Seddon, P. J. (2009). Habituation potential of yellow-eyed penguins depends on sex, character and previous experience with humans. Animal 
Behaviour, 77, 289-296.

Ellenberg, U., Mattern, T., \& Seddon, P. J. (2013). Heart rate responses provide an objective evaluation of human disturbance stimuli in breeding birds. Conservation Physiology, 1, cot013.

Frid, A., \& Dill, L. M. (2002). Human-caused disturbance stimuli as a form of predation risk. Conservation Ecology, 6, 11.

Geffroy, B., Samia, D. S. M., Bessa, E., \& Blumstein, D. T. (2015). How nature-based tourism might increase prey vulnerability to predators. Trends in Ecology and Evolution, 30, 755-765.

Gill, J. A., Norris, K., \& Sutherland, W. J. (2001). Why behavioural responses may not reflect the population consequences of human disturbance. Biological Conservation, 97, 265-268.

Goodall, J. (1986). The chimpanzees of Gombe: patterns of behavior. Cambridge, MA: Harvard University Press.

Groves, P. M., \& Thompson, R. F. (1970). Habituation: a dual-process theory. Psychological Review, 77, 419-450.

Harnad, S. E. (Ed.) (1987). Categorical perception. Cambridge: Cambridge University Press.

Henderson, C. R. (1975). Best linear unbiased estimation and prediction under a selection model. Biometrics, 423-447.

Herrero, S., Smith, T., DeBruyn, T. D., Gunther, K., \& Matt, C. A. (2005). From the field: brown bear habituation to people—-safety, risks, and benefits. Wildlife Society Bulletin, 33, 362-373. 
Ikuta, L. A., \& Blumstein, D. T. (2003). Do fences protect birds from human disturbance? Biological Conservation, 112, 447-452.

Jensen, E. L., Dill, L. M., \& Cahill Jr, J. F. (2011). Applying behavioral-ecological theory to plant defense: light-dependent movement in Mimosa pudica suggests a trade-off between predation risk and energetic reward. The American Naturalist, 177, 377-381.

Kasereka, B., Muhigwa, J.-B. B., Shalukoma, C., \& Kahekwa, J. M. (2006).

Vulnerability of habituated Grauer's gorilla to poaching in the Kahuzi-Biega National Park, DRC. African Study Monographs, 27, 15-26.

King, L. E., Douglas-Hamilton, I., \& Vollrath, F. (2007). African elephants run from the sound of disturbed bees. Current Biology, 17, R832-R833.

Klein, M. L., Humphrey, S. R., \& Percival, H. F. (1995). Effects of ecotourism on distribution of waterbirds in a wildlife refuge. Conservation Biology, 9, 1454-1465.

Kloppers, E. L., St. Clair, C. C., \& Hurd, T. E. (2005). Predator-resembling aversive conditioning for managing habituated wildlife. Ecology and Society, 10, 31.

Leigh, J., \& Chamberlain, M. J. (2008). Effects of aversive conditioning on behavior of nuisance Louisiana black bears. Human-Wildlife Conflicts, 2, 175-182.

Li, C., Monclús, R., Maul, T. L., Jiang, Z., \& Blumstein, D. T. (2011). Quantifying human disturbance on antipredator behavior and flush initiation distance in yellowbellied marmots. Applied Animal Behaviour Science, 129, 146-152.

Liesenjohann, T., \& Eccard, J. (2008). Foraging under uniform risk from different types of predators. BMC Ecology, 8, 19.

Lima, S. L., \& Zollner, P. A. (1996). Towards a behavioral ecology of ecological landscapes. Trends in Ecology and Evolution, 11, 131-135. 
Mccleery, R. A. (2009). Changes in fox squirrel anti-predator behavior across the urbanrural gradient. Landscape Ecology, 24, 483-493.

Møller, A. P. (2009). Basal metabolic rate and risk - taking behaviour in birds. Journal of Evolutionary Biology, 22, 2420-2429.

Møller, A. P. (2015). Birds. In W. E. Cooper, Jr. \& D. T. Blumstein (Eds.), Escaping from predators: an integrative view of escape decisions (pp. 88-112). Cambridge: Cambridge University Press.

Møller, A. P., \& Erritzøe, J. (2010). Flight distance and eye size in birds. Ethology, 116, $458-465$.

Møller, A. P., \& Garamszegi, L. Z. (2012). Between individual variation in risk-taking behavior and its life history consequences. Behavioral Ecology, 23, 843-853.

Møller, A. P., Samia, D. S., Weston, M. A., Guay, P.-J., \& Blumstein, D. T. (2014). American Exceptionalism: Population trends and flight initiation distances in birds from three continents. PloS ONE, 9, e107883.

Naughton - Treves, L. (1998). Predicting patterns of crop damage by wildlife around Kibale National Park, Uganda. Conservation Biology, 12, 156-168.

Nisbet, I. C. (2000). Disturbance, habituation, and management of waterbird colonies. Waterbirds, 23, 312-332.

Northridge, S. P. (1991). An updated world review of interactions between marine mammals and fisheries. FAO Fisheries Technical Paper. No. 251, Suppl. 1, Rome: Food \& Agriculture Organization.

Nowak, K., le Roux, A., Richards, S. A., Scheijen, C. P. J., \& Hill, R. A. (2014). Human observers impact habituated monkeys' perceived landscape of fear. Behavioral 
Ecology, 25, 1199-1204.

O'Connell-Rodwell, C. E., Rodwell, T., Rice, M., \& Hart, L. A. (2000). Living with the modern conservation paradigm: can agricultural communities co-exist with elephants? A five-year case study in East Caprivi, Namibia. Biological Conservation, 93, 381-391.

Owens, N.W. (1977). Responses of wintering brent geese to human disturbance. Wildfowl, $28,5-14$.

Petelle, M. B., McCoy, D. E., Alejandro, V., Martin, J. G. A., \& Blumstein, D. T. (2013). Development of boldness and docility in yellow-bellied marmots. Animal Behaviour, $86,1147-1154$.

Price, M. V., Strombom, E. H., \& Blumstein, D. T. (2014). Human activity affects the perception of risk by mule deer. Current Zoology, 60, 693-699.

Raderschall, C. A., Magrath, R. D., \& Hemmi, J. M. (2011). Habituation under natural conditions: model predators are distinguished by approach direction. The Journal of Experimental Biology, 214, 4209-4216.

Rankin, C. H., Abrams, T., Barry, R. J., Bhatnagar, S., Clayton, D. F., Colombo, J., . . . Marsland, S. (2009). Habituation revisited: an updated and revised description of the behavioral characteristics of habituation. Neurobiology of Learning and Memory, 92, $135-138$.

Relyea, R. A. (2003). How prey respond to combined predators: a review and an empirical test. Ecology, 84, 1827-1839.

Rhoades, E., \& Blumstein, D. T. (2007). Predicted fitness consequences of threatsensitive hiding behavior. Behavioral Ecology, 18, 937-943. 
Rodríguez-Prieto, I., \& Fernández-Juricic, E. (2005). Effects of direct human disturbance on the endemic Iberian frog Rana iberica at individual and population levels. Biological Conservation, 123, 1-9.

Sagarin, R. D., Alcorta, C. S., Atran, S., Blumstein, D. T., Dietl, G. P., Hochberg, M. E., . . Madin, J. S. (2010). Decentralize, adapt and cooperate. Nature, 465, 292-293.

Samia, D. S. M., \& Blumstein, D. T. (2014). Phi index: a new metric to test the flush early and avoid the rush hypothesis. PloS ONE, 9, e113134.

Samia, D. S. M., Blumstein, D. T., Stankowich, T., \& Cooper, W. E. (2015). Fifty years of chasing lizards: new insights advance optimal escape theory. Biological Reviews doi: 10.1111/brv.12173.

Samia, D. S. M., Nakagawa, S., Nomura, F., Rangel, T. F., \& Blumstein, D. T. (2015). Increased tolerance to humans among disturbed wildlife. Nature Communications, 6 , 8877.

Samia, D. S. M., Nomura, F., \& Blumstein, D. T. (2013). Do animals generally flush early and avoid the rush? A meta-analysis. Biology Letters, 9, 20130016.

Schakner, Z., \& Blumstein, D. T. (2016). Learning and conservation behavior: an introduction and overview. In O. Berger-Tal \& D. Saltz (Eds.), Conservation behavior: applying behavioral ecology to wildlife conservation and management (6692). Cambridge: Cambridge University Press.

Schakner, Z. A., \& Blumstein, D. T. (2013). Behavioral biology of marine mammal deterrents: a review and prospectus. Biological Conservation, 167, 380-389.

Shannon, G., Cordes, L. S., Hardy, A. R., Angeloni, L. M., \& Crooks, K. R. (2014). Behavioral responses associated with a human-mediated predator shelter. PloS ONE, 
9, e94630.

Shivik, J. A. (2006). Tools for the edge: what's new for conserving carnivores. BioScience, 56, 253-259.

Shivik, J. A., Treves, A., \& Callahan, P. (2003). Nonlethal techniques for managing predation: primary and secondary repellents. Conservation Biology, 17, 1531-1537.

Sih, A. (2013). Understanding variation in behavioural responses to human-induced rapid environmental change: a conceptual overview. Animal Behaviour, 85, 1077-1088.

Smith, T. S., Herrero, S., \& DeBruyn, T. D. (2005). Alaska brown bears, humans, and habituation. Ursus, 16, 1-10.

Stankowich, T., \& Blumstein, D. T. (2005). Fear in animals: a meta-analysis and review of risk assessment. Proceedings of the Royal Society B: Biological Sciences, 272, 2627-2634.

Stankowich, T., \& Reimers, E. (2015). Mammals. In W. E. Cooper, Jr. \& D. T. Blumstein (Eds.), Escaping from predators: an integrative view of escape decisions (pp. 63-87). Cambridge: Cambridge University Press.

St. Clair, C. C., Found, R., Gangadharan, A., \& Murray, M. (2016). Behavior-based contributions to reserve design and management. In O. Berger-Tal \& D. Saltz (Eds.), Conservation Behavior: applying behavioral ecology to wildlife conservation and management (pp. 176-211). Cambridge: Cambridge University Press.

Steketee, J. D., \& Kalivas, P. W. (2011). Drug wanting: behavioral sensitization and relapse to drug-seeking behavior. Pharmacological Reviews, 63, 348-365.

Steven, R., Pickering, C., \& Castley, J. G. (2011). A review of the impacts of nature based recreation on birds. Journal of Environmental Management, 92, 2287-2294. 
Symonds, M. R., Weston, M. A., Robinson, R. W., \& Guay, P.-J. (2014). Comparative analysis of classic brain component sizes in relation to flightiness in birds. PloS ONE, 9, e91960.

Tarlow, E., \& Blumstein, D. T. (2007). Evaluating methods to quantify anthropogenic stressors on animals. Applied Animal Behaviour Science, 102, 429-451.

Tyrrell, L. P., \& Fernández-Juricic, E. (2015). Sensory systems and escape behavior. In W. E. Cooper, Jr. \& D. T. Blumstein (Eds.), Escaping from predators: an integrative view of escape decisions (pp. 322-342) Cambridge: Cambridge University Press.

Van Horne, B. (1983). Density as a misleading indicator of habitat quality. Journal of Wildlife Management, 47, 893-901.

Viblanc, V. A., Smith, A. D., Gineste, B., \& Groscolas, R. (2012). Coping with continuous human disturbance in the wild: insights from penguin heart rate response to various stressors. BMC Ecology, 12, 10.

Walters, C. J., \& Holling, C. S. (1990). Large-scale management experiments and learning by doing. Ecology, 71, 2060-2068.

Waser, N. M., Price, M. V., Blumstein, D. T., Arózqueta, S. R., Escobar, B. D. C., Pickens, R., \& Pistoia, A. (2014). Coyotes, deer, and wildflowers: diverse evidence points to a trophic cascade. Naturwissenschaften, 101, 427-436.

Webb, N. V., \& Blumstein, D. T. (2005). Variation in human disturbance differentially affects predation risk assessment in western gulls. The Condor, 107, 178-181.

Werner, S. J., \& Clark, L. (2006). Effectiveness of a motion-activated laser hazing system for repelling captive Canada geese. Wildlife Society Bulletin, 34, 2-7.

Wilson, J. P., Friedman, M. J., \& Lindy, J. D., Eds. (2001). Treating psychological 
trauma and PTSD. The Guilford Press, New York.

Ydenberg, R. C., \& Dill, L. M. (1986). The economics of fleeing from predators. Advances in the Study of Behavior, 16, 229-249.

Zimmermann, B., Nelson, L., Wabakken, P.. Sand, H., \& Liberg, O. (2014). Behavioral responses of wolves to roads: scale-dependent ambivalence. Behavioral Ecology, 25, 1353-1364. 